\title{
Central effects of GLP-1: new opportunities for treatments of neurodegenerative diseases
}

\section{Christian Hölscher}

Division of Biomedical and Life Sciences, Faculty of Health and Medicine, Lancaster University, Lancaster LA1 4YQ, UK
Correspondence should be addressed to $\mathrm{C}$ Hölscher

Email

Christian_holscher@mac.com

\begin{abstract}
The incretin hormone glucagon-like peptide 1 (GLP-1) has many effects in the body. It is best known for the 'incretin effect', facilitating insulin release from the pancreas under hyperglycaemic conditions. Building on this, GLP-1 mimetics have been developed as a treatment for type 2 diabetes. In the course of monitoring of patients, it has become apparent that GLP-1 mimetics have a range of other physiological effects in the body. In preclinical trials, a substantial body of evidence has been built that these mimetics have neuroprotective and anti-inflammatory effects. GLP-1 also has very similar growth-factorlike properties to insulin, which is presumably the underlying basis of the neuroprotective effects. In preclinical studies of Alzheimer's disease (AD), Parkinson's disease (PD), stroke and other neurodegenerative disorders, it has been shown that most GLP-1 mimetics cross the blood-brain barrier and show impressive neuroprotective effects in numerous studies. In animal models of AD, GLP-1 mimetics such as exendin-4, liraglutide and lixisenatide have shown protective effects in the CNS by reducing $\beta$-amyloid plaques, preventing loss of synapses and memory impairments, and reducing oxidative stress and the chronic inflammatory response in the brain. In animal models of PD, exendin-4 showed protection of dopaminergic neurons in the substantia nigra and prevention of dopamine loss in the basal ganglia while preserving motor control. These encouraging findings have spawned several clinical trials, some of which have shown encouraging initial results. Therefore, GLP-1 mimetics show great promise as a novel treatment for neurodegenerative conditions.
\end{abstract}

\author{
Key Words \\ - neurodegeneration \\ - Alzheimer's disease \\ - Parkinson's disease \\ - amyotrophic lateral sclerosis \\ - stroke \\ - ischaemia \\ - incretins \\ - multiple sclerosis \\ - glucagon-like peptide 1
}

Journal of Endocrinology (2014) 221, T31-T41

\section{Introduction}

The main hallmark of type 2 diabetes mellitus (T2DM) is insulin desensitisation. The discovery that the incretin hormone glucagon-like peptide 1 (GLP-1) facilitates insulin release during episodes of hyperglycaemia and has several additional properties to overcome insulin desensitisation made GLP-1 an ideal candidate as a treatment for diabetes (see Bayliss \& Starling (1902) and reviews in this special issue). Several drugs have been developed and brought onto the market as treatments, and therefore, GLP-1 is primarily known in the context of diabetes. However, it has become apparent that GLP-1 has additional properties as well, which have not been researched to such a high degree as its properties in maintaining normoglycaemia. 


\section{Insulin desensitisation can occur in the brain}

Recent research has shown that insulin desensitisation can also occur in the brain. In several patient database analyses, T2DM has been identified as a risk factor for Alzheimer's disease (AD) and Parkinson's disease (PD), indicating that insulin desensitisation in the periphery may be a factor in initiating or accelerating the development of neurodegenerative processes (Moroo et al. 1994, Aviles-Olmos et al. 2012). Several epidemiological studies found a correlation between T2DM and an increased risk of developing AD or other neurodegenerative disorders at a later stage in life (Luchsinger et al. 2004, Ristow 2004, Strachan 2005, Biessels et al. 2006, Haan 2006). One study by the Mayo clinic showed a clear correlation between T2DM and AD. In this study, $85 \%$ of $\mathrm{AD}$ patients had either T2DM or increased fasting glucose levels, compared with $42 \%$ in the age-matched non-demented control group (Leibson et al. 1997). In a different study, T2DM had been identified as a risk factor that doubled the chances of developing AD (Janson et al. 2004). In a longitudinal study, an oral glucose tolerance test showed an increased risk of developing $\mathrm{AD}$ in people with elevated 2-h postload glucose levels (Ohara et al. 2011). In general, reduced insulin sensitivity and efficacy is commonly observed in elderly people and contributes to the development of $\mathrm{AD}$ (Carro \& Torres-Aleman 2004b, Hoyer 2004).

Importantly, biochemical studies of brain tissue demonstrate that insulin signalling in the brain is desensitised in $\mathrm{AD}$ patients, and the brain tissue shows a very similar profile to that in diabetic people with respect to insulin signalling biomarkers of desensitisation in the periphery (Steen et al. 2005, Lester-Coll et al. 2006, Talbot et al. 2012). In an initial study, insulin receptor levels were found to be phosphorylated and expression levels downregulated in the brains of patients with $\mathrm{AD}$ (Steen et al. 2005). In a histological study of AD brain tissue, IGF1 and insulin receptors were found to be internalised in neurons, and the second messengers insulin receptor substrate 1 (IRS1) and IRS2 were reduced in total levels but had increased levels of phospho- Ser ${ }^{312}$ (Moloney et al. 2010). Furthermore, in a recent study, it was found that in brain tissue of AD patients, IGF1 and insulin signalling was strongly desensitised. Phosphorylation of the insulin receptor $\beta$ chain was reduced at positions $\operatorname{IR} \beta \mathrm{pY}^{1150 / 1151}$ and IR $\beta \mathrm{pY}^{960}$, while the IRS1 was hyperphosphorylated at positions IRS1 $\mathrm{pS}^{616}$ and IRS1 $\mathrm{pS}^{636}$, which deactivates IRS1 signalling, and IRS1 binding to phosphatidylinositol 3kinase (PI3K) p85 $\alpha$ was also much reduced. In addition, it was found in a $\mathrm{AD}$ brain tissue incubation study that treating brain tissue with insulin induced a reduced downstream second messenger activation (Talbot et al. 2012). The observed biochemical changes were very pronounced and also occurred in $\mathrm{AD}$ patients that were not diabetic. This type of CNS insulin signalling desensitisation is not dependent on glucose levels.

Initial studies of patients with PD found similar biochemical changes in insulin signalling in brain regions that are relevant to this disease. It was found that the levels of insulin receptor phosphorylation were increased in the basal ganglia and the substantia nigra (Moroo et al. 1994). Furthermore, increased IRS2 phosphorylation, a marker of IGF1 resistance, was found in the basal ganglia of the 6-hydroxydopamine lesion rat model of PD (Morris et al. 2008). Animal studies show similar changes. In a high-fat mouse model of T2DM, learning and memory and synaptic plasticity in the brain were impaired (Porter et al. 2010b). In a high-fat-diet rat model of early-stage T2DM, insulin resistance was observed while dopamine release was attenuated and dopamine clearance was diminished in the basal ganglia, indicating that dopaminergic signalling is compromised in T2DM (Morris et al. 2011).

This unexpected connection between T2DM and $\mathrm{AD} / \mathrm{PD}$ opened up novel research avenues to investigate what the underlying mechanisms for this may be. Insulin is a hormone that has a range of functions in the body. Its general physiological profile is that of a growth factor (see Fig. 1). As a growth factor, insulin plays an important role in cell growth and survival. Neurons also carry insulin receptors, and activating these induces dendritic sprouting, neuronal stem cell activation and general cell growth, repair and neuroprotection (van Dam \& Aleman 2004, Hoyer 2004, Stockhorst et al. 2004, Holscher 2005, Li \& Hölscher 2007). In addition, insulin has potent neuroprotective effects against stressors (Carro \& Torres-Aleman 2004a, Li \& Hölscher 2007). Insulin enhances brain functions such as attention, memory formation and cognition in humans (Watson \& Craft 2004, Zhao et al. 2004, Okereke et al. 2008, Reger et al. 2008a). When administered by nasal application where it enters the brain more directly, insulin improved attention and memory formation (Craft 2007, Reger et al. $2008 a, b)$. Importantly, a phase II clinical trial showed that nasal application of insulin improved cognition in patients with mild cognitive impairments (MCI), considered to be the early phase of AD. It further improved the amyloid140:1-42 ratio in cerebrospinal fluid (CSF), increased the cortical activation as seen in fluorodeoxyglucose-positron emission tomography scans and also showed improvement in mental tasks (Craft 2010). Several follow-up clinical

Published by Bioscientifica Ltd 


\section{Pathways and functions of insulin receptor activation}

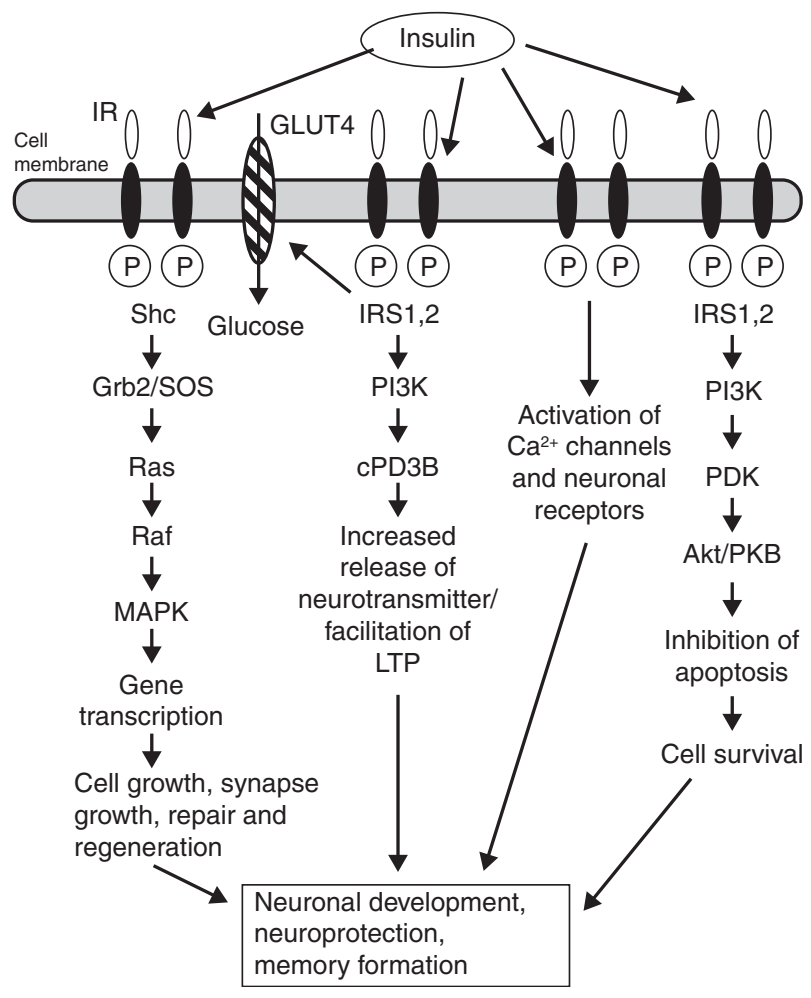

Figure 1

Insulin signalling in neurons. The insulin receptor (IR) is expressed on neurons and activates growth factor-type cell signalling pathways. The IR plays an important role in neuronal growth, synaptic development and control of neurotransmitter release at the synapse. Its role in glucose uptake is limited in neurons, as the insulin-dependent GLUT-4 glucose uptake transporter is only expressed in a sub-population of large excitatory neurons (Benomar et al. 2006, Grillo et al. 2009). Insulin binds to the $\alpha$-subunit of the receptor. This activates the tyrosine kinase phosphorylation of the $\beta$-subunit. This activates second messenger pathways. (1) Activation of the insulin receptor MAP kinase pathway activates growth-related gene expression required for the control of cell metabolism and energy homeostasis, cell growth, synapse growth and for cell repair and maintenance (Hoyer 1997, Biessels et al. 2006). (2) Insulin also modulates synaptic neurotransmission and primes synapses for induction of long-term potentiation of synaptic transmission (LTP; Biessels et al. 2004). This pathway most probably involves binding of IRS1 to activate the phosphatidylinositol 3-kinase (PI3K; Zhao et al. 2000). This may prime the synapse for increased neurotransmitter vesicle release (de la Monte \& Wands 2006). Modulation of neurotransmission may be the basis for memory formation and information processing in the CNS (Hölscher 1999).

studies have started (e.g. http://clinicaltrials.gov/ct2/show/ NCT01767909?term=insulin+AND+Alzheimer\&rank=1). For a review, see Freiherr et al. (2013).

One possibility for the development of neurodegenerative disorders is an impairment in signalling by growth factors such as insulin and IGF1. The desensitisation would reduce vital gene expression for cell repair and growth and could put neurons at an increased risk over time if additional stressors occur (Holscher 2011). Neurons do not divide and cannot be replaced, and most of them live for the duration of a person's lifetime. The amount of actual neurogenesis is far too insufficient to compensate for the loss. This means neurons are exposed to stressors over a long time frame, and damage may accumulate over decades and will finally result in synaptic loss and neuronal dysfunction and ultimately, neuronal death (Holscher 2011).

\section{GLP-1 mimetics have neuroprotective properties}

AS T2DM had been identified as a risk factor for $\mathrm{AD}$, the concept developed that drugs that can treat T2DM successfully may also have neuroprotective properties. In diabetes, a range of drugs is on the market or under development, which could be tested for potential neuroprotective properties. As described in this special issue, use of mimetics of the incretin GLP-1 is a successful strategy to treat T2DM (Holst 2004, Drucker \& Nauck 2006, Campbell $\&$ Drucker 2013). Not only have a range of effective and long-lasting mimetics been developed and tested, three of these have received approval as treatments for T2DM (Madsbad et al. 2011, Elkinson \& Keating 2013). In the brain, GLP-1 receptors are expressed by neurons, in particular on pyramidal neurons in the hippocampus and neocortex, and Purkinje cells in the cerebellum (During et al. 2003, Perry et al. 2007, Hamilton \& Holscher 2009). Glia cells were not found to express this receptor but induced expression when activated in an inflammatory response (Iwai et al. 2006). In initial studies of synaptic plasticity in the hippocampus, we found that novel GLP-1 analogues such as Val8GLP-1, liraglutide or exendin-4, which are dipeptidyl peptidase 4 protease-resistant and have a much enhanced biological half-life in the body (Holst 2004), have profound effects on memory formation and on synaptic plasticity in the brain (Holscher 2010). In addition, GLP-1 mimetics can protect synapses from the detrimental effects that $\beta$-amyloid has on synaptic plasticity in the hippocampus (Gault \& Holscher 2008). Most of these novel mimetics can cross the blood-brain barrier (Kastin et al. 2002, Kastin \& Akerstrom 2003, McClean et al. 2011, Hunter \& Holscher 2012, McGovern et al. 2012), a property that is of vital importance if they are to be used to treat neurodegenerative disorders of the CNS.

GLP-1 is a growth factor, and the neuroprotective effects are most probably due to classic growth factor effects such as increased expression of genes that are

Published by Bioscientifica Ltd 
linked to cell growth and repair and replacement, increase of cell metabolism, inhibition of apoptosis and reduction of inflammatory responses (see Fig. 2 for details on the underlying molecular mechanisms). Other growth factors have shown similar neuroprotective properties (Bradbury 2005, Kuipers \& Bramham 2006). However, most neuroprotective growth factors such as nerve growth factor and brain-derived neurotrophic factor do not cross the bloodbrain barrier and therefore have no protective effect in the CNS when injected peripherally (Holscher 2011).

\section{GLP-1 mimetics have anti-inflammatory properties}

Progressive neurodegenerative diseases as well as stroke induce a chronic inflammatory response in the brain. This secondary downstream process causes further neurodegenerative effects via the activation of immune cells such as microglia in the brain. These cells release proinflammatory cytokines and free radicals such as nitric oxide (NO), which is neurotoxic (Ayasolla et al. 2004). The degenerative effects of chronic inflammation in the brain

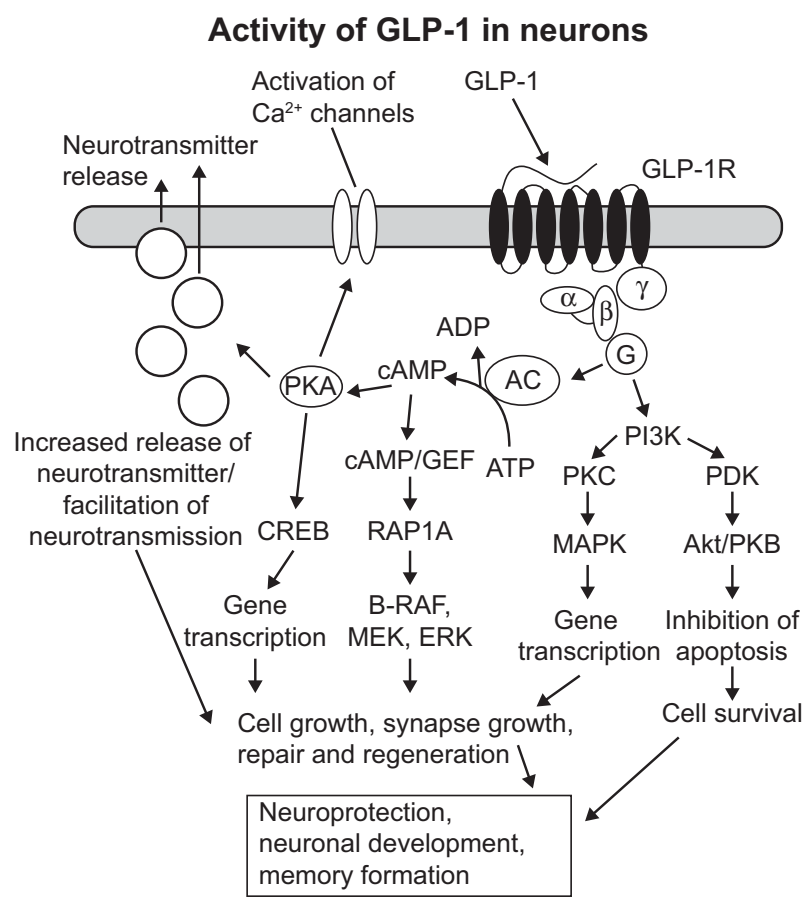

Figure 2

Overview of the main pathways induced by GLP-1 in neurons. The GLP-1 receptor is a member of a different classes of receptors compared with the IR. Activation of the GLP-1R activates an adenylyl cyclase and increases CAMP levels. This activates PKA and other downstream kinases that are related to growth factor signalling. This may be the reason why GLP-1 mimetics can compensate for insulin desensitisation in diabetics and in AD. For more details, see Holscher (2010) and Holscher \& Li (2010). are extensive (Arnon \& Aharoni 2009), and intense research into anti-inflammatory drugs for such conditions is currently ongoing (Aisen 2002, Cole et al. 2004, Griffin 2008, Lee et al. 2010).

It is therefore of great interest to note that GLP-1 mimetics are not only neuroprotective but also have antiinflammatory properties. One study demonstrated that both activated microglia and activated astrocytes, which take part in the immune/inflammatory response, induce GLP-1 receptor expression. GLP-1 treatment prevents an endotoxin (lipopolysaccharide (LPS))-induced release of the cytokine IL1 $\beta$ by these cells (Iwai et al. 2006). IL1 $\beta$ is pro-inflammatory and reduces neuronal transmission while increasing apoptosis-related signalling. Furthermore, exendin- 4 can reduce monocyte adhesion to aortic endothelium in an inflammatory response in atherosclerosis and also prevents LPS-induced cytokine and chemokine release in both human and mouse monocytes (Arakawa et al. 2010) and an increase in microvascular permeability (Dozier et al. 2009). LPS activates a systemic inflammatory response, as bacterial walls contain molecules of this class. In our study of chronic treatment, the amyloid precursor protein (APP)/presenilin-1 (PS1) mouse model of AD with liraglutide injected i.p., the numbers of activated microglia in the brain was much reduced (McClean et al. 2011). As this effect may be due to the reduction of amyloid plaque, we followed up this study with a second study that measured the effects of liraglutide on inflammation only. X-ray exposure is known to induce an inflammatory response. We found that the main pro-inflammatory cytokines and NO syntheses in the brains of X-ray-exposed mice (6 Gray) after 30 days of i.p. once-daily injections of liraglutide was significantly reduced (Parsarathy \& Holscher 2011).

These data indicate that GLP-1 mimetics may be useful in treating the chronic inflammatory response seen in neurodegenerative disorders.

\section{Alzheimer's disease}

In preclinical studies of established animal models of $\mathrm{AD}$, neuroprotective effects were observed. In the APP/PS1 transgenic mouse model of $\mathrm{AD}$, which expresses the human Swedish mutated form of APP and a mutated human form of PS-1, both mutations which lead to AD, it was found that chronic i.p. injection of the GLP-1 mimetic $\operatorname{Val}(8)$ GLP-1 blocked synaptic degradation that is observed in this AD mouse model and rescued synaptic plasticity in the hippocampus (Gengler et al. 2012). In rats that received i.c.v. injections of $\beta$-amyloid, a protein that

Published by Bioscientifica Ltd 
accumulates in the brains of AD patients, it was found that Val(8)GLP-1 prevented the blocking of synaptic plasticity in the brain and prevented the impairment of spatial learning (Wang et al. 2010). In a separate study, the GLP-1 mimetic liraglutide also protected synapses from the detrimental effects of $\beta$-amyloid and rescued memory formation (McClean et al. 2011, Han et al. 2013). Liraglutide (Victoza) is on the market as a treatment for T2DM (Courreges et al. 2008). When tested in the APP/PS1 mouse model of $\mathrm{AD}$, once-daily injections i.p. had clear neuroprotective effects. Liraglutide prevented the memory impairment that is usually observed in ageing APP/PS1 mice, protected the synapses in the hippocampus from degradation and furthermore protected synaptic plasticity. The $\beta$ amyloid plaque load and the total amount of $\beta$-amyloid in the brain were much reduced. This is an important biomarker for $\mathrm{AD}$, and a reduction in amyloid levels is an important beneficial property. Furthermore, the chronic inflammatory response that is found in the brains of the $\mathrm{AD}$ mouse model was also much reduced (McClean et al. 2011). Exendin-4 has also been shown to reduce endogenous levels of $\beta$-amyloid in the mouse brain (Perry et al. 2003). This drug is also on the market as a treatment for T2DM under the name Byeatta. Exendin-4 has a range of neuroprotective properties in transgenic mouse models of AD (Li et al. 2010) and cell culture studies (Perry \& Greig 2005). GLP-1 mimetics have also been shown to induce neurite outgrowth and to protect against excitotoxic cell death in cell cultures (Perry et al. 2002, 2007). Furthermore, mice that overexpressed GLP-1 receptors in the hippocampus showed increased neurite growth and improved learning (During et al. 2003). GLP-1 mimetics, exendin- 4 as well as liraglutide and lixisenatide, also normalise neuronal progenitor cell proliferation and neurogenesis. It has been demonstrated in several studies in mouse models of $\mathrm{AD}$ and of diabetes or in wildtype mice that incretin analogues can increase or normalise neuronal progenitor cell proliferation in the CNS (During et al. 2003, Li et al. 2010, Porter et al. 2010a,b, Hamilton et al. 2011, McClean et al. 2011, Hunter \& Holscher 2012).

In conclusion, GLP-1 mimetics show an impressive range of protective effects on synaptogenesis, neurogenesis, cell repair and the reduction of the chronic inflammatory response and most importantly reduce the levels of amyloid plaques in the brain. These findings indicate that these drugs may be used as novel treatments for AD (Azzouz et al. 2004, Bradbury 2005, Cotman et al. 2007, Gregory-Evans et al. 2009, Holscher 2011).

\section{Parkinson's disease}

There are several preclinical studies that have demonstrated neuroprotective effects of exendin- 4 in animal models of PD. The protective effects of exendin- 4 on neural stem/progenitor cells in the subventricular zone in the rat brain and the beneficial effects in an animal model of PD as well as in cell culture had been tested (Bertilsson et al. 2008). Exendin-4 increased the number of neural stem/progenitor cells in cell culture experiments. Furthermore, in an in vivo experiment, i.p. injection of exendin- 4 enhanced the numbers of BrdU-positive progenitor cells in the subventricular zone. Neuronal precursor cell counts were also increased, suggesting that new neurons form that may compensate for the loss of dopaminergic neurons in the substantia nigra (Bertilsson et al. 2008). Exendin-4 was injected i.p. to test its effect in the 6-hydroxy-dopamine (6-OHDA) PD animal model which demonstrates neuronal loss in the substantia nigra. Five weeks after unilateral 6-OHDA lesion, the rats received i.p. injections of extendin- 4 for 3 weeks. In a functional test of the dopaminergic system, amphetamine was injected, which that enhances dopamine release in the basal ganglia. A reduction of rotations in the movement of the exendin-4 group demonstrated a reduced functional impairment in this group. The expression of dopaminesynthesis-related enzymes was also elevated in the drug group. This result demonstrates that exendin- 4 has cellular and functional beneficial properties in protecting rodents from the loss of dopaminergic neurons and transmission induced by 6-OHDA (Bertilsson et al. 2008). This was confirmed in a second study that employed the 6-OHDA and the LPS-induced substantia nigra injection lesion model of PD, which were used to test the effects of exendin-4. Seven days after inducing the pharmacological lesions, exendin- 4 was injected i.p. After 7 days of treatment, amphetamine-induced circling behaviour was reduced in the exendin-4 groups. The levels of dopamine measured in the basal ganglia were also increased. Histological markers also confirmed that dopamine production was increased compared with the lesion-only groups (Harkavyi et al. 2008). An additional study tested exendin- 4 in cultured dopaminergic rat neurons. These cells are vulnerable to 6-OHDA exposure. Exendin-4 protected the neurons taken from wild-type mice, but not those taken from GLP-1-receptor-knockout mice. In an in vivo study, exendin-4 protected dopaminergic neurons and rescued motor function in the 1-methyl-4phenyl-1,2,3,6-tetrahydropyridine lesion mouse model of PD (Li et al. 2009).

Published by Bioscientifica Ltd 
Patient data analyses also confirmed that a higher percentage of PD patients were diabetic or had elevated levels of glucose compared with age-matched control subjects. It was found that $8-30 \%$ of PD patients are diabetic, a significantly higher percentage compared with age-matched controls (Pressley et al. 2003, Aviles-Olmos et al. 2012). Based on the encouraging preclinical studies, a clinical trial testing exendin-4 in PD patients has been conducted (see below).

\section{Amyotrophic lateral sclerosis}

A different progressive neurodegenerative disorder that may be treated with GLP-1 mimetics is amyotrophic lateral sclerosis (ALS). The dominant symptom is increased motor neuron degeneration in the cortex, the brain stem and spinal cord. As a consequence, patients with ALS show fast developing paralysis and muscle wasting and die within 3-5 years after diagnosis, mainly due to respiratory failure (Kunst 2004).

In order to test the effects of exendin- 4 in this disease, the drug was tested in NSC-19 neuroblastoma cells and a mouse model of ALS (SOD1 G93A mutant mice). It was found that exendin-4 protected NSC-19 cells and elevated the biomarker for acetylcholine neurotransmission, choline acetyltransferase (ChAT) activity and also protected cells from hydrogen peroxide-induced stress. The SOD1 mutant mice were treated with exendin- 4 from 6 weeks of age onwards until the final stage of disease progression. The drug-treated SOD1 mice had near normal motor activity. In histological analyses, extending 4-treated mice had a reduced rate of degeneration of motor neurons in the spinal cord. In immunohistochemical analyses, motor neuron markers such as ChAT were normalised (Li et al. 2012). In a different approach, injection of cells that release GLP-1 into the brains of SOD1 mice, their survival was significantly extended and motor impairment and weight loss were much delayed. In motor activity analysis, an improvement of function was also observed. The chronic inflammatory response in the CNS was also reduced (Knippenberg et al. 2012). These neuroprotective effects of the GLP-1 mimetic exendin-4 support the concept that GLP-1 signalling is neuroprotective and may be a treatment strategy for ALS.

\section{Peripheral neuropathy}

Peripheral neuropathy is a degeneration of the neurons of the peripheral nervous system and can be induced by a range of causes. In chronic T2DM, peripheral neuropathy is often observed. To test the potential neuroprotective effect of exendin-4, the drug was tested in the diabetic polyneuropathy that is found in the streptozotocin (STZ) animal model of diabetes. STZ is toxic to $\beta$ cells in the pancreas and reduces insulin production. The effects of GLP-1 (7-37) or exendin-4 were tested in cultured dorsal ganglion neurons from the peripheral nervous system. Both drugs accelerated the neurite outgrowth of cultured ganglion neurons. In the STZ-induced diabetes mouse model, exendin- 4 was injected i.p. for 4 weeks. When testing the motor and sensory nerve conduction velocity of peripheral nerves, both GLP-1 (7-37) and exendin-4 protected the conduction of neurons. In behavioural tests, pain perceptions and motor and sensory neuronal conduction were improved by exendin-4. In histological studies, the skin nerve fibre densities were also normalised by exendin-4 (Himeno et al. 2011). Exendin-4 has been tested in a different model of peripheral neuropathy that was induced by vitamin B6 overdose. In anatomical studies, axon sizes were normalised by GLP-1. In motor tasks, the rats were partially protected from the effects of high B6 doses (Perry et al. 2007). Again, GLP-1 signalling has neuroprotective effects on peripheral neuropathy and may be of use in treating patients with such conditions.

\section{Ischaemia and stroke}

The anti-inflammatory properties and the neuroprotective effects of GLP-1 mimetics indicate that these drugs may be useful in treating stroke victims. Exendin- 4 showed good neuroprotection in a transient middle cerebral artery occlusion stroke model in rats. It was found that exendin4 reduced the brain area that degenerated after the stroke had been induced. In a functional score of motor activity, the drug-treated group performed better (Li et al. 2009). In a transient cerebral ischaemia model in gerbils, the effect of exendin-4 treatment was measured for the hippocampal CA1 region. It was found that GLP-1 receptor expression was increased after 1 day, and GLP-1R immunoreactivity was found not only in pyramidal neurons but also in astrocytes and GABAergic interneurons. Exendin-4 reversed the ischaemia-induced hyperactivity, reduced neuronal loss and also reduced microglial inflammatory activation in a dose-dependent manner (Lee et al. 2011). A further study tested the neuroprotective effect of exendin-4 injected i.v. after a 60-min focal cerebral ischaemia induction. The drug reduced infarct volume and protected the mice from motor impairment. It also reduced oxidative stress, induction of an inflammatory response and neuronal death after reperfusion (Teramoto et al. 2011). In a neuronal

Published by Bioscientifica Ltd 
cell culture study, exendin- 4 showed good neuroprotection under hypoxic conditions. This process was dependent on PKA the kinase that is activated by the GLP-1 receptor via adenylyl cyclase activation (Wang et al. 2012).

Taken together, these preclinical studies demonstrate good efficiency of GLP-1 signalling in protecting neurons from stressors and in reducing the inflammatory response in stroke and ischaemia. GLP-1 mimetics therefore show promise in preventing some of the secondary damage that occurs after a stroke or an ischaemic insult.

\section{Multiple sclerosis}

Considering that GLP-1 mimetics have anti-inflammatory properties and also protect synapses from stressors, it appears that these drugs may have beneficial effects in multiple sclerosis. The main hallmarks of this disease are continuous or intermittent inflammatory responses that seem to be directed against the myelin sheath that insulates larger axons. A strong inflammatory response that causes the loss of myelin sheaths slows axonal signal conduction and also results in loss of synapses and finally neuronal loss and impairment of motor control (Arnon \& Aharoni 2009, Rossi et al. 2012). At present, no scientific publications are available on the effects of GLP-1 mimetics in animal models of multiple sclerosis. However, a patent is available that reports the effects of exendin- 4 in mouse models of multiple sclerosis ('GLP-1 receptor agonists for treating autoimmune disorders' (WO 2011/024110A2) by the companies Pfizer and Rinat).

In this patent, the experimental results of the effects of exendin-4 and GLP-1 in several mouse models of multiple sclerosis are reported. One mouse model named Experimental Autoimmune Encephalomyelitis (EAE) involves the active immunisation of mice with membrane components of myelin such as the myelin basic protein, proteolipid protein and myelin oligodendrocyte glycoprotein. This induces an autoimmune response and develop ascending paralysis. The development of this autoimmune response can be acute or chronic, depending on the mouse strain and the myelin proteins used in the immunisation. Further hallmarks of EAE are a strong inflammatory response, mainly induced lymphocytes and macrophages that infiltrate the brain, followed by demyelination in the CNS (Arnon \& Aharoni 2009, Aharoni et al. 2011, Rossi et al. 2012).

The experimental studies analysed spinal cord sections for infiltrating cells, $\mathrm{T}$ cells, monocytes and microglia. The level of demyelinisation was also assessed. Cytokine levels of Il-17 and interferon- $\gamma$ were measured.
The motor activity of the mice was also scored, and survival times were quantified. The motor impairment in the mice was reduced by exendin-4, and life expectancy was increased. The main inflammatory responses, such as T-cell proliferation and activation, as well as the inflammatory cell invasion into the CNS were much reduced, as was the level of demyelinisation. In addition, the cytokine release in the spleen was reduced.

These preclinical results are encouraging and indicate that GLP-1 mimetics may have beneficial effects in patients with multiple sclerosis. It is important to note, however, that the scientific results presented in the patent have not been peer reviewed.

\section{Clinical trials}

The preclinical studies listed above show an impressive range of neuroprotective and anti-inflammatory effects of GLP-1 mimetics. Furthermore, since three GLP-1 mimetics are already on the market as treatments for T2DM with a good safety profile in chronic use, several clinical trials have started that investigate the neuroprotective effects of exendin- 4 or liraglutide in PD or AD patients. GLP-1 analogues have low-to-absent potential for inducing hypoglycaemia, as this propriety makes them potentially suitable as safe treatments for non-hyperglycaemic conditions such as neurological disorders.

\section{Parkinson's disease}

Recently, a clinical trial of exendin- 4 in PD patients has been completed. This proof of concept study tested the effects of exendin- 4 in a randomised open-label trial in 45 patients. The drug was given for 12 months followed by a 2-month washout period. The drug group was compared with a matched group that did not receive an injection. It was found that exendin- 4 was well tolerated, although weight loss was common. In a single-blinded rating of the drug group, clinically relevant improvements in PD across motor and cognitive measures were compared with those in the control group. Exenatide-treated patients had a mean improvement at 12 months on the Movement Disorder Society-sponsored revision of the Unified Parkinson's Disease Rating Scale (MDS-UPDRS) of 2.7 points, compared with mean decline of 2.2 points in control patients $(P=0.037)$. Most interestingly, exendin- 4 showed a clear improvement in the Mattis dementia rating scale 2 (DRS-2) cognitive score, suggesting that exendin-4 has beneficial effects in the CNS on cognition and memory (Aviles-Olmos et al. 2013).

Published by Bioscientifica Ltd 


\section{Alzheimer's disease}

A randomised, double-blind clinical trial to assess the safety and efficacy of exendin-4 treatment in 230 MCI patients/early phase $\mathrm{AD}$ is currently ongoing at the National Institutes of Health (NIH)/National Institute on Aging (NIA) in the USA. This trial will take 3 years, with exendin- 4 given. The outcomes are performance in the Clinical Dementia Rating scale sum-of-boxes, Alzheimer's Disease Assessment scale cognitive sub-scale, behavioural and cognitive performance measures, changes on structural and functional MRI and MRS, hormonal and metabolic changes and changes in cerebrospinal fluid and plasma $\mathrm{AD}$ biomarkers (http:// clinicaltrials.gov/ct2/show/NCT01255163?term=exendin$4+$ AND+alzheimer\&rank $=1$ ).

A small-scale trial with 34 patients has been completed in Denmark at the University of Aarhus, but the results have not been published yet. This double-blind, randomised trial tests the effects of liraglutide vs placebo on MCI patients, using FDG-PET imaging to estimate glucose uptake in neurons and Pittsburgh compound B-PET imaging to measure plaque load, cognitive tests were also scheduled, see Egefjord et al. (2012) for details of the study design. A caveat regarding this study is that it is underpowered to produce meaningful results. (ClinicalTrials.gov Identifier: NCT01469351).

A second large-scale phase II clinical trial with liraglutide in $206 \mathrm{MCI}$ patients has started. This trial is being conducted by Imperial College London. The trial has a randomised and placebo-controlled double-blind design and will analyse FDG-PET signal changes in neuronal metabolism and cortical activation, inflammation markers (microglia activation) in PET imaging, will take CSF samples for inflammation markers and amyloid/tau levels and the change in z-scores for the Alzheimer's Disease Assessment Scale Executive (ADAS Exec), and MRI changes. It will take 12 months, with a drug dose of $1.8 \mathrm{mg}$ subcutaneously per day in the drug group or placebo injection (http:// clinicaltrials.gov/ct2/show/NCT01843075?term=liraglutide+and+alzheimer\&rank=1).

\section{Conclusions}

The preclinical experimental results demonstrate a wide range of important neuroprotective properties in engaging the therapeutic targets associated with neurodegenerative disease, such as impaired memory, synapse loss and impaired neuronal communication/synaptic plasticity, $\beta$-amyloid plaque formation (AD), motor function impairment, dopaminergic neuronal loss and dopaminergic loss in the basal ganglia (PD), chronic inflammation and reduced neuronal regeneration and neurogenesis (stroke MS, ALS). As GLP-1 mimetics are already on the market to treat T2DM and are well tolerated (Nauck 2011) and show a range of additional benefits (Ussher \& Drucker 2012), and clinical trials in patients with $\mathrm{PD}$ or $\mathrm{AD}$ testing the effects of exendin-4 or liraglutide have been started, GLP-1R activation shows great promise of being helpful in treating a range of neurodegenerative disorders (Holscher 2010).

\section{Declaration of interest}

The author declares that there is no conflict of interest that could be perceived as prejudicing the impartiality of the review.

\section{Funding}

Part of the work described here was funded by the Alzheimer Research UK and the Alzheimer Society UK charities. Prof. C Hölscher has been a consultant and invited speaker for the following drug companies: NovoNordisk, Novartis, Sanofi, Eli Lilly, Amylin and Pfizer. He is a named inventor on three patent applications for the use of GLP-1 or GIP analogues in neurodegenerative diseases.

\section{References}

Aharoni R, Vainshtein A, Stock A, Eilam R, From R, Shinder V \& Arnon R 2011 Distinct pathological patterns in relapsing-remitting and chronic models of experimental autoimmune enchephalomyelitis and the neuroprotective effect of glatiramer acetate. Journal of Autoimmunity 37 228-241. (doi:10.1016/j.jaut.2011.06.003)

Aisen PS 2002 The potential of anti-inflammatory drugs for the treatment of Alzheimer's disease. Lancet Neurology 1 279-284. (doi:10.1016/S14744422(02)00133-3)

Arakawa M, Mita T, Azuma K, Ebato C, Goto H, Nomiyama T, Fujitani Y, Hirose T, Kawamori R \& Watada H 2010 Inhibition of monocyte adhesion to endothelial cells and attenuation of atherosclerotic lesion by a glucagon-like peptide-1 receptor agonist, exendin-4. Diabetes 59 1030-1037. (doi:10.2337/db09-1694)

Arnon R \& Aharoni R 2009 Neuroprotection and neurogeneration in MS and its animal model EAE effected by glatiramer acetate. Journal of Neural Transmission 116 1443-1449. (doi:10.1007/s00702-009-0272-3)

Aviles-Olmos I, Limousin P, Lees A \& Foltynie T 2012 Parkinson's disease, insulin resistance and novel agents of neuroprotection. Brain 136374-384. (doi:10.1093/brain/aws009)

Aviles-Olmos I, Dickson J, Kefalopoulou Z, Djamshidian A, Ell P, Soderlund T, Whitton P, Wyse R, Isaacs T, Lees A et al. 2013 Exenatide and the treatment of patients with Parkinson's disease. Journal of Clinical Investigation 123 2730-2736. (doi:10.1172/JCI68295)

Ayasolla K, Khan M, Singh AK \& Singh I 2004 Inflammatory mediator and $\beta$-amyloid (25-35)-induced ceramide generation and iNOS expression are inhibited by vitamin E. Free Radical Biology \& Medicine 37 325-338. (doi:10.1016/j.freeradbiomed.2004.04.007)

Azzouz M, Ralph GS, Storkebaum E, Walmsley LE, Mitrophanous KA, Kingsman SM, Carmeliet P \& Mazarakis ND 2004 VEGF delivery with retrogradely transported lentivector prolongs survival in a mouse ALS model. Nature 429 413-417. (doi:10.1038/nature02544)

Bayliss W \& Starling E 1902 On the causation of the so-called 'peripheral reflex secretion' of the pancreas. Proceedings of the Royal Society of London, Series B: Biological Sciences 69 352-252. (doi:10.1098/rspl.1901.0119)

Published by Bioscientifica Ltd 
Benomar Y, Naour N, Aubourg A, Bailleux V, Gertler A, Djiane J, Guerre-Millo M \& Taouis M 2006 Insulin and leptin induce Glut4 plasma membrane translocation and glucose uptake in a human neuronal cell line by a phosphatidylinositol 3-kinase-dependent mechanism. Endocrinology 147 2550-2556. (doi:10.1210/en.20051464)

Bertilsson G, Patrone C, Zachrisson O, Andersson A, Dannaeus K, Heidrich J, Kortesmaa J, Mercer A, Nielsen E, Ronnholm H et al. 2008 Peptide hormone exendin-4 stimulates subventricular zone neurogenesis in the adult rodent brain and induces recovery in an animal model of Parkinson's disease. Journal of Neuroscience Research 86 326-338. (doi:10. 1002/jnr.21483)

Biessels GJ, Bravenboer B \& Gispen WH 2004 Glucose, insulin and the brain: modulation of cognition and synaptic plasticity in health and disease: a preface. European Journal of Pharmacology 490 1-4. (doi:10. 1016/j.ejphar.2004.02.057)

Biessels GJ, De Leeuw FE, Lindeboom J, Barkhof F \& Scheltens P 2006 Increased cortical atrophy in patients with Alzheimer's disease and type 2 diabetes mellitus. Journal of Neurology, Neurosurgery, and Psychiatry $\mathbf{7 7}$ 304-307. (doi:10.1136/jnnp.2005.069583)

Bradbury J 2005 Hope for AD with NGF gene-therapy trial. Lancet Neurology 4 335. (doi:10.1016/S1474-4422(05)70086-7)

Campbell JE \& Drucker DJ 2013 Pharmacology, physiology, and mechanisms of incretin hormone action. Cell Metabolism 17 819-837. (doi:10.1016/j.cmet.2013.04.008)

Carro E \& Torres-Aleman I 2004a The role of insulin and insulin-like growth factor I in the molecular and cellular mechanisms underlying the pathology of Alzheimer's disease. European Journal of Pharmacology 490 127-133. (doi:10.1016/j.ejphar.2004.02.050)

Carro E \& Torres-Aleman I 2004b Insulin-like growth factor I and Alzheimer's disease: therapeutic prospects? Expert Review of Neurotherapeutics 4 79-86. (doi:10.1586/14737175.4.1.79)

Cole GM, Morihara T, Lim GP, Yang F, Begum A \& Frautschy SA 2004 NSAID and antioxidant prevention of Alzheimer's disease: lessons from in vitro and animal models. Annals of the New York Academy of Sciences 1035 68-84. (doi:10.1196/annals.1332.005)

Cotman CW, Berchtold NC \& Christie LA 2007 Exercise builds brain health: key roles of growth factor cascades and inflammation. Trends in Neurosciences 30 464-472. (doi:10.1016/j.tins.2007.06.011)

Courreges JP, Vilsboll T, Zdravkovic M, Le-Thi T, Krarup T, Schmitz O, Verhoeven R, Buganova I \& Madsbad S 2008 Beneficial effects of once-daily liraglutide, a human glucagon-like peptide- 1 analogue, on cardiovascular risk biomarkers in patients with type 2 diabetes. Diabetic Medicine 25 1129-1131. (doi:10.1111/j.1464-5491.2008.02484.x)

Craft S 2007 Insulin resistance and Alzheimer's disease pathogenesis: potential mechanisms and implications for treatment. Current Alzheimer Research 4 147-152. (doi:10.2174/156720507780362137)

Craft S 2010 A randomized, placebo-controlled trial of intranasal insulin in amnestic MCI and early Alzheimer's. In ICAD Conference, pp abstr. P3-455. Hawaii, USA.

van Dam P \& Aleman A 2004 Insulin-like growth factor-I, cognition and brain aging. European Journal of Pharmacology 490 87-95. (doi:10.1016/ j.ejphar.2004.02.047)

Dozier KC, Cureton EL, Kwan RO, Curran B, Sadjadi J \& Victorino GP 2009 Glucagon-like peptide-1 protects mesenteric endothelium from injury during inflammation. Peptides 30 1735-1741. (doi:10.1016/j.peptides. 2009.06.019)

Drucker DJ \& Nauck MA 2006 The incretin system: glucagon-like peptide-1 receptor agonists and dipeptidyl peptidase-4 inhibitors in type 2 diabetes. Lancet 368 1696-1705. (doi:10.1016/S0140-6736(06)69705-5)

During MJ, Cao L, Zuzga DS, Francis JS, Fitzsimons HL, Jiao X, Bland RJ, Klugmann M, Banks WA, Drucker DJ et al. 2003 Glucagon-like peptide1 receptor is involved in learning and neuroprotection. Nature Medicine 9 1173-1179. (doi:10.1038/nm919)

Egefjord L, Gejl M, Moller A, Braendgaard H, Gottrup H, Antropova O, Moller N, Poulsen HE, Gjedde A, Brock B et al. 2012 Effects of liraglutide on neurodegeneration, blood flow and cognition in Alzheimer s disease protocol for a controlled, randomized double-blinded trial. Danish Medical Journal 59 A4519.

Elkinson S \& Keating GM 2013 Lixisenatide: first global approval. Drugs 73 383-391. (doi:10.1007/s40265-013-0033-3)

Freiherr J, Hallschmid M, Frey WH II, Brunner YF, Chapman CD, Holscher C, Craft S, De Felice FG \& Benedict C 2013 Intranasal insulin as a treatment for Alzheimer's disease: a review of basic research and clinical evidence. CNS Drugs 27 505-514. (doi:10.1007/s40263-013-0076-8)

Gault V \& Holscher C 2008 GLP-1 agonists facilitate hippocampal LTP and reverse the impairment of LTP induced by $\beta$-amyloid. European Journal of Pharmacology 587 112-117. (doi:10.1016/j.ejphar.2008.03.025)

Gengler S, McClean P, McCurtin R, Gault V \& Holscher C 2012 Val(8)GLP-1 rescues synaptic plasticity and reduces dense core plaques in APP/PS1 mice. Neurobiology of Aging 33 265-276. (doi:10.1016/j.neurobiolaging. 2010.02.014)

Gregory-Evans K, Chang F, Hodges MD \& Gregory-Evans CY 2009 Ex vivo gene therapy using intravitreal injection of GDNF-secreting mouse embryonic stem cells in a rat model of retinal degeneration. Molecular Vision 15 962-973.

Griffin WS 2008 Perispinal etanercept: potential as an Alzheimer therapeutic. Journal of Neuroinflammation 5 3. (doi:10.1186/1742-2094-5-3)

Grillo CA, Piroli GG, Hendry RM \& Reagan LP 2009 Insulin-stimulated translocation of GLUT4 to the plasma membrane in rat hippocampus is PI3-kinase dependent. Brain Research 1296 35-45. (doi:10.1016/j. brainres.2009.08.005)

Haan MN 2006 Therapy insight: type 2 diabetes mellitus and the risk of late-onset Alzheimer's disease. Nature Clinical Practice. Neurology 2 159-166. (doi:10.1038/ncpneuro0124)

Hamilton A \& Holscher C 2009 Receptors for the insulin-like peptide GLP-1 are expressed on neurons in the CNS. Neuroreport 20 1161-1166. (doi:10.1097/WNR.0b013e32832fbf14)

Hamilton A, Patterson S, Porter D, Gault VA \& Holscher C 2011 Novel GLP-1 mimetics developed to treat type 2 diabetes promote progenitor cell proliferation in the brain. Journal of Neuroscience Research 89 481489. (doi:10.1002/jnr.22565)

Han W-N, Holscher C, Yuan L, Yang W, Wang X-h, Wu M-N \& Qi J-S 2013 Liraglutide protects against $\beta$-amyloid induced impairment of spatial learning and memory in rats. Neurobiology of Aging 32 576-588. (doi:10. 1016/j.neurobiolaging.2012.04.009)

Harkavyi A, Abuirmeileh A, Lever R, Kingsbury AE, Biggs CS \& Whitton PS 2008 Glucagon-like peptide 1 receptor stimulation reverses key deficits in distinct rodent models of Parkinson's disease. Journal of Neuroinflammation 5 19. (doi:10.1186/1742-2094-5-19)

Himeno T, Kamiya H, Naruse K, Harada N, Ozaki N, Seino Y, Shibata T, Kondo M, Kato J, Okawa T et al. 2011 Beneficial effects of exendin- 4 on experimental polyneuropathy in diabetic mice. Diabetes 60 2397-2406. (doi:10.2337/db10-1462)

Hölscher C 1999 Synaptic plasticity and learning and memory: LTP and beyond. Journal of Neuroscience Research 58 62-75. (doi:10.1002/ (SICI) 1097-4547(19991001)58:1 < 62::AID-JNR7 > 3.0.CO;2-G)

Holscher C 2005 Development of $\beta$-amyloid-induced neurodegeneration in Alzheimer's disease and novel neuroprotective strategies. Reviews in the Neurosciences 16 181-212. (doi:10.1515/REVNEURO.2005.16.3.181)

Holscher C 2010 Incretin analogues that have been developed to treat type 2 diabetes hold promise as a novel treatment strategy for Alzheimer's disease. Recent Patents on CNS Drug Discovery 5 109-117. (doi:10.2174/ $157488910791213130)$

Holscher C 2011 Diabetes as a risk factor for Alzheimer's disease: insulin signalling impairment in the brain as an alternative model of Alzheimer's disease. Biochemical Society Transactions 39 891-897. (doi:10.1042/BST0390891)

Holscher C \& Li L 2010 New roles for insulin-like hormones in neuronal signalling and protection: new hopes for novel treatments of Alzheimer's disease? Neurobiology of Aging 31 1495-1502. (doi:10.1016/ j.neurobiolaging.2008.08.023) 
Holst JJ 2004 Treatment of type 2 diabetes mellitus with agonists of the GLP-1 receptor or DPP-IV inhibitors. Expert Opinion on Emerging Drugs 9 155-166. (doi:10.1517/14728214.9.1.155)

Hoyer S 1997 Models of Alzheimer's disease: cellular and molecular aspects. Journal of Neural Transmission 49 11-21. (doi:10.1007/978-3-7091-6844-8_2)

Hoyer S 2004 Glucose metabolism and insulin receptor signal transduction in Alzheimer's disease. European Journal of Pharmacology 490 115-125. (doi:10.1016/j.ejphar.2004.02.049)

Hunter K \& Holscher C 2012 Drugs developed to treat diabetes, liraglutide and lixisenatide, cross the blood brain barrier and enhance neurogenesis. BMC Neuroscience 13 33-38. (doi:10.1186/1471-2202-13-33)

Iwai T, Ito S, Tanimitsu K, Udagawa S \& Oka J 2006 Glucagon-like peptide-1 inhibits LPS-induced IL-1 $\beta$ production in cultured rat astrocytes. Neuroscience Research 55 352-360. (doi:10.1016/j.neures.2006.04.008)

Janson J, Laedtke T, Parisi JE, O’Brien P, Petersen RC \& Butler PC 2004 Increased risk of type 2 diabetes in Alzheimer's disease. Diabetes $\mathbf{5 3}$ 474-481. (doi:10.2337/diabetes.53.2.474)

Kastin AJ \& Akerstrom V 2003 Entry of exendin-4 into brain is rapid but may be limited at high doses. International Journal of Obesity and Related Metabolic Disorders 27 313-318. (doi:10.1038/sj.ijo.0802206)

Kastin AJ, Akerstrom V \& Pan W 2002 Interactions of glucagon-like peptide-1 (GLP-1) with the blood-brain barrier. Journal of Molecular Neuroscience 18 7-14. (doi:10.1385/JMN:18:1-2:07)

Knippenberg S, Thau N, Dengler R, Brinker T \& Petri S 2012 Intracerebroventricular injection of encapsulated human mesenchymal cells producing glucagon-like peptide- 1 prolongs survival in a mouse model of ALS. PLOS ONE 7 e36857. (doi:10.1371/journal.pone.0036857)

Kuipers SD \& Bramham CR 2006 Brain-derived neurotrophic factor mechanisms and function in adult synaptic plasticity: new insights and implications for therapy. Current Opinion in Drug Discovery \& Development 9 580-586.

Kunst C 2004 Complex genetics of amyotrophic lateral sclerosis. American Journal of Human Genetics 75 933-947. (doi:10.1086/426001)

Lee YJ, Han SB, Nam SY, Oh KW \& Hong JT 2010 Inflammation and Alzheimer's disease. Archives of Pharmacal Research 33 1539-1556. (doi:10.1007/s12272-010-1006-7)

Lee CH, Yan B, Yoo KY, Choi JH, Kwon SH, Her S, Sohn Y, Hwang IK, Cho JH, Kim YM et al. 2011 Ischemia-induced changes in glucagon-like peptide-1 receptor and neuroprotective effect of its agonist, exendin-4, in experimental transient cerebral ischemia. Journal of Neuroscience Research 89 1103-1113. (doi:10.1002/jnr.22596)

Leibson CL, Rocca WA, Hanson VA, Cha R, Kokmen E, O'Brien PC \& Palumbo PJ 1997 Risk of dementia among persons with diabetes mellitus: a population-based cohort study. American Journal of Epidemiology 145 301-308. (doi:10.1093/oxfordjournals.aje.a009106)

Lester-Coll N, Rivera EJ, Soscia SJ, Doiron K, Wands JR \& de la Monte SM 2006 Intracerebral streptozotocin model of type 3 diabetes: relevance to sporadic Alzheimer's disease. Journal of Alzheimer's Disease 9 13-33.

Li L \& Hölscher C 2007 Common pathological processes in Alzheimer's disease and type 2 diabetes: a review. Brain Research Reviews 56 384-402. (doi:10.1016/j.brainresrev.2007.09.001)

Li Y, Perry T, Kindy MS, Harvey BK, Tweedie D, Holloway HW, Powers K, Shen H, Egan JM, Sambamurti K et al. 2009 GLP-1 receptor stimulation preserves primary cortical and dopaminergic neurons in cellular and rodent models of stroke and Parkinsonism. PNAS 106 1285-1290. (doi:10.1073/pnas.0806720106)

Li Y, Duffy K, Ottinger M, Ray B, Bailey J, Holloway H, Tweedie D, Perry T, Mattson M, Kapogiannis D et al. 2010 GLP-1 receptor stimulation reduces amyloid- $\beta$ peptide accumulation and cytotoxicity in cellular and animal models of Alzheimer's disease. Journal of Alzheimer's Disease 19 1205-1219. (doi:10.3233/JAD-2010-1314)

Li Y, Chigurupati S, Holloway HW, Mughal M, Tweedie D, Bruestle DA, Mattson MP, Wang Y, Harvey BK, Ray B et al. 2012 Exendin-4 ameliorates motor neuron degeneration in cellular and animal models of amyotrophic lateral sclerosis. PLOS ONE 7 e32008. (doi:10.1371/ journal.pone.0032008)
Luchsinger JA, Tang MX, Shea S \& Mayeux R 2004 Hyperinsulinemia and risk of Alzheimer's disease. Neurology 63 1187-1192. (doi:10.1212/01. WNL.0000140292.04932.87)

Madsbad S, Kielgast U, Asmar M, Deacon C, Torekov SS \& Holst JJ 2011 An overview of once-weekly GLP-1 receptor agonists - available efficacy and safety data and perspectives for the future. Diabetes, Obesity \& Metabolism 13 394-407. (doi:10.1111/j.1463-1326.2011.01357.x)

McClean P, Parthsarathy V, Faivre E \& Hölscher C 2011 The diabetes drug Liraglutide prevents degenerative processes in a mouse model of Alzheimer's disease. Journal of Neuroscience 31 6587-6594. (doi:10. 1523/JNEUROSCI.0529-11.2011)

McGovern S, Kerry H \& Holscher C 2012 Effects of the glucagon-like polypeptide-1 analogue (Val8)GLP-1 on learning, progenitor cell proliferation and neurogenesis in the $\mathrm{C} 57 \mathrm{~B} / 16$ mouse brain. Brain Research 1473 204-213. (doi:10.1016/j.brainres.2012.07.029)

Moloney AM, Griffin RJ, Timmons S, O'Connor R, Ravid R \& O'Neill C 2010 Defects in IGF-1 receptor, insulin receptor and IRS-1/2 in Alzheimer's disease indicate possible resistance to IGF-1 and insulin signalling. Neurobiology of Aging 31 224-243. (doi:10.1016/j.neurobiolaging.2008. 04.002)

de la Monte SM \& Wands JR 2006 Molecular indices of oxidative stress and mitochondrial dysfunction occur early and often progress with severity of Alzheimer's disease. Journal of Alzheimer's Disease 9 167-181.

Moroo I, Yamada T, Makino H, Tooyama I, McGeer PL, McGeer EG \& Hirayama K 1994 Loss of insulin receptor immunoreactivity from the substantia nigra pars compacta neurons in Parkinson's disease. Acta Neuropathologica 87 343-348. (doi:10.1007/BF00313602)

Morris JK, Zhang H, Gupte AA, Bomhoff GL, Stanford JA \& Geiger PC 2008 Measures of striatal insulin resistance in a 6-hydroxydopamine model of Parkinson's disease. Brain Research 1240 185-195. (doi:10.1016/j. brainres.2008.08.089)

Morris JK, Bomhoff GL, Gorres BK, Davis VA, Kim J, Lee PP, Brooks WM, Gerhardt GA, Geiger PC \& Stanford JA 2011 Insulin resistance impairs nigrostriatal dopamine function. Experimental Neurology 231 171-180. (doi:10.1016/j.expneurol.2011.06.005)

Nauck MA 2011 Incretin-based therapies for type 2 diabetes mellitus: properties, functions, and clinical implications. American Journal of Medicine 124 S3-18. (doi:10.1016/j.amjmed.2010.11.002)

Ohara T, Doi Y, Ninomiya T, Hirakawa Y, Hata J, Iwaki T, Kanba S \& Kiyohara Y 2011 Glucose tolerance status and risk of dementia in the community: the Hisayama Study. Neurology 77 1126-1134. (doi:10. 1212/WNL.0b013e31822f0435)

Okereke OI, Selkoe DJ, Pollak MN, Stampfer MJ, Hu FB, Hankinson SE \& Grodstein F 2008 A profile of impaired insulin degradation in relation to late-life cognitive decline: a preliminary investigation. International Journal of Geriatric Psychiatry 24 177-182. (doi:10.1002/gps.2089)

Parsarathy V \& Holscher C 2011 The novel GLP1 analogue, Liraglutide, reduces inflammation in a mouse model of brain tissue injury. In Society for Neuroscience Annual Meeting. Washington, DC.

Perry T \& Greig NH 2005 Enhancing central nervous system endogenous GLP-1 receptor pathways for intervention in Alzheimer's disease. Current Alzheimer Research 2 377-385. (doi:10.2174/ 1567205054367892)

Perry T, Haughey NJ, Mattson MP, Egan JM \& Greig NH 2002 Protection and reversal of excitotoxic neuronal damage by glucagon-like peptide- 1 and exendin-4. Journal of Pharmacology and Experimental Therapeutics 302 881-888. (doi:10.1124/jpet.102.037481)

Perry T, Lahiri DK, Sambamurti K, Chen D, Mattson MP, Egan JM \& Greig NH 2003 Glucagon-like peptide-1 decreases endogenous amyloid- $\beta$ peptide $(A \beta)$ levels and protects hippocampal neurons from death induced by A $\beta$ and iron. Journal of Neuroscience Research 72 603-612. (doi:10.1002/jnr.10611)

Perry T, Holloway HW, Weerasuriya A, Mouton PR, Duffy K, Mattison JA \& Greig NH 2007 Evidence of GLP-1-mediated neuroprotection in an animal model of pyridoxine-induced peripheral sensory neuropathy. Experimental Neurology 203 293-301. (doi:10.1016/j.expneurol.2006.09.028) 
Porter DW, Irwin N, Flatt PR, Holscher C \& Gault VA 2010a Prolonged GIP receptor activation improves cognitive function, hippocampal synaptic plasticity and glucose homeostasis in high-fat fed mice. European Journal of Pharmacology 650 688-693. (doi:10.1016/j.ejphar.2010.10.059) Porter DW, Kerr BD, Flatt PR, Holscher C \& Gault VA $2010 b$ Four weeks administration of Liraglutide improves memory and learning as well as glycaemic control in mice with high fat dietary-induced obesity and insulin resistance. Diabetes, Obesity \& Metabolism 12 891-899. (doi:10. 1111/j.1463-1326.2010.01259.x)

Pressley JC, Louis ED, Tang MX, Cote L, Cohen PD, Glied S \& Mayeux R 2003 The impact of comorbid disease and injuries on resource use and expenditures in Parkinsonism. Neurology 60 87-93. (doi:10.1212/WNL. 60.1.87)

Reger MA, Watson GS, Green PS, Baker LD, Cholerton B, Fishel MA, Plymate SR, Cherrier MM, Schellenberg GD, Frey WH II et al. 2008 a Intranasal insulin administration dose-dependently modulates verbal memory and plasma amyloid- $\beta$ in memory-impaired older adults. Journal of Alzheimer's Disease 13 323-331.

Reger MA, Watson GS, Green PS, Wilkinson CW, Baker LD, Cholerton B, Fishel MA, Plymate SR, Breitner JC, DeGroodt W et al. 2008b Intranasal insulin improves cognition and modulates $\beta$-amyloid in early AD. Neurology 70 440-448. (doi:10.1212/01.WNL.0000265401.62434.36)

Ristow M 2004 Neurodegenerative disorders associated with diabetes mellitus. Journal of Molecular Medicine 82 510-529. (doi:10.1007/ s00109-004-0552-1)

Rossi S, Furlan R, De Chiara V, Motta C, Studer V, Mori F, Musella A, Bergami A, Muzio L, Bernardi G et al. 2012 Interleukin-1 $\beta$ causes synaptic hyperexcitability in multiple sclerosis. Annals of Neurology $\mathbf{7 1}$ 76-83. (doi:10.1002/ana.22512)

Steen E, Terry BM, Rivera E, Cannon JL, Neely TR, Tavares R, Xu XJ, Wands JR \& de la Monte SM 2005 Impaired insulin and insulin-like growth factor expression and signaling mechanisms in Alzheimer's disease - is this type 3 diabetes? Journal of Alzheimer's Disease 7 63-80.

Stockhorst U, de Fries D, Steingrueber HJ \& Scherbaum WA 2004 Insulin and the CNS: effects on food intake, memory, and endocrine parameters and the role of intranasal insulin administration in humans. Physiology \& Behavior 83 47-54. (doi:10.1016/j.physbeh.2004. 07.022)

Strachan MW 2005 Insulin and cognitive function in humans: experimental data and therapeutic considerations. Biochemical Society Transactions 33 1037-1040. (doi:10.1042/BST20051037)

Talbot K, Wang HY, Kazi H, Han LY, Bakshi KP, Stucky A, Fuino RL, Kawaguchi KR, Samoyedny AJ, Wilson RS et al. 2012 Demonstrated brain insulin resistance in Alzheimer's disease patients is associated with IGF-1 resistance, IRS-1 dysregulation, and cognitive decline. Journal of Clinical Investigation 122 1316-1338. (doi:10.1172/JCI59903)

Teramoto S, Miyamoto N, Yatomi K, Tanaka Y, Oishi H, Arai H, Hattori N \& Urabe T 2011 Exendin-4, a glucagon-like peptide-1 receptor agonist, provides neuroprotection in mice transient focal cerebral ischemia. Journal of Cerebral Blood Flow and Metabolism 31 1696-1705. (doi:10. 1038/jcbfm.2011.51)

Ussher JR \& Drucker DJ 2012 Cardiovascular biology of the incretin system. Endocrine Reviews 33 187-215. (doi:10.1210/er.2011-1052)

Wang XH, Li L, Holscher C, Pan YF, Chen XR \& Qi JS 2010 Val8-glucagonlike peptide- 1 protects against A $\beta 1-40$-induced impairment of hippocampal late-phase long-term potentiation and spatial learning in rats. Neuroscience 170 1239-1248. (doi:10.1016/j.neuroscience.2010.08.028)

Wang MD, Huang Y, Zhang GP, Mao L, Xia YP, Mei YW \& Hu B 2012 Exendin-4 improved rat cortical neuron survival under oxygen/glucose deprivation through PKA pathway. Neuroscience 226 388-396. (doi:10. 1016/j.neuroscience.2012.09.025)

Watson GS \& Craft S 2004 Modulation of memory by insulin and glucose: neuropsychological observations in Alzheimer's disease. European Journal of Pharmacology 490 97-113. (doi:10.1016/j.ejphar.2004.02.048)

Zhao AZ, Shinohara MM, Huang D, Shimizu M, Eldar-Finkelman H, Krebs EG, Beavo JA \& Bornfeldt KE 2000 Leptin induces insulin-like signaling that antagonizes cAMP elevation by glucagon in hepatocytes. Journal of Biological Chemistry 275 11348-11354. (doi:10.1074/jbc.275. 15.11348)

Zhao WQ, Chen H, Quon MJ \& Alkon DLw 2004 Insulin and the insulin receptor in experimental models of learning and memory. European Journal of Pharmacology 490 71-81. (doi:10.1016/j.ejphar.2004.02.045)

Received in final form 18 August 2013

Accepted 2 September 2013

Accepted Preprint published online 2 September 2013
() 2014 Society for Endocrinology Printed in Great Britain
Published by Bioscientifica Ltd 